\title{
Psychiatric Co-Morbidity and Quality of Life in Egyptian Type 2 Diabetic Patients
}

\author{
Alaa Wafa1, Mohamed Adel El-Hadidy² \\ ${ }^{1}$ Internal Medicine Department, Diabetes and Endocrine Unit, Mansoura Faculty of Medicine, Mansoura, Egypt \\ ${ }^{2}$ Psychiatry Department, Mansoura Faculty of Medicine, Mansoura, Egypt \\ Email: dralaawafa@hotmail.com, elhadidyy@gmail.com
}

How to cite this paper: Wafa, A. and ElHadidy, M.A. (2016) Psychiatric Co-Morbidity and Quality of Life in Egyptian Type 2 Diabetic Patients. International Journal of Clinical Medicine, 7, 756-765.

http://dx.doi.org/10.4236/ijcm.2016.711082

Received: October 8, 2016

Accepted: November 26, 2016

Published: November 29, 2016

Copyright $\odot 2016$ by authors and Scientific Research Publishing Inc. This work is licensed under the Creative Commons Attribution International License (CC BY 4.0).

http://creativecommons.org/licenses/by/4.0/ (c) (i) Open Access

\begin{abstract}
Background: Diabetes is a risk factor for depression, but little is known about anxiety and other psychiatric disorders and quality of life. The aim of this study was to assess the prevalence of depression, anxiety in diabetic patients in our locality and to assess the quality of life in type $2 \mathrm{DM}$. Subjects \& Methods: This study was a cross-sectional study and was carried out in outpatient clinics of specialized medical hospital, Mansoura university for a period of one year. From 217 diabetes mellitus subjects, only 202 patients were matched with 247 healthy people as a control group. All subjects were examined by using socioeconomic data, clinical data, and anthropometric examinations to assess body mass index and waist circumference. All patients were interviewed by using the Mini-International Neuropsychiatric Interview (MINI) version 5, MINI, Hospital Anxiety and Depression scale (HAD) and health-related quality of life (HRQOL) scales. Laboratory investigation in the form of fasting and twohour postprandial blood sugar (FBS \& $2 \mathrm{hpp}$ ) and $\mathrm{HbA1C}$ levels were done. Results: $18.3 \%$ were found to be major depressive disorder; and $2.5 \%$ panic disorder, $1 \%$ other phobia. Generalized anxiety disorder and obsessive-compulsive disorder were found in one patient, no patients were found to be diagnosed as Bipolar disorder, schizophrenia, or substance abuse. Although there was no statistically significant difference between subjects and control groups regarding height, there was statistically significant difference between weights, BMI, with more scores among DM group. Moreover our study showed that $\mathrm{HbA1c}$, fasting blood sugar, two hours post prandial blood sugar were more among DM patients and control groups. Anxiety, depression, and poorer quality of life were found to be more prevalent among DM patients than control groups. Conclusion: DM is associated with depression anxiety disorder with poorer quality of life.
\end{abstract}

\section{Keywords}

Diabetes, Stress, Anxiety, Depression, Psychiatric Co-Morbidities, Diabetic Complications, Glycemic Control 


\section{Introduction}

An individual's health behavior is influenced by his or her social, economic, cultural, and physical environment. Medical experts have reported on the psychological components of almost all diseases, particularly chronic illnesses such as diabetes mellitus [1].

Diabetes increases the risk of depression. In a meta-analysis, the odds of having depression were two-fold in patients with diabetes compared with those without [2]. In addition, anxiety and eating disorders have also been reported to be common in patients with diabetes [3]. The prevalence of anxiety disorders among patients with diabetes is considerably higher compared to the general population [4]. Anxiety symptoms have been found to be significant risk factors for development of diabetes [5]. Negative correlations have been observed between prevalence of anxiety disorders and levels of HbA1c [6].

Quality of life is difficult to define. It is further complicated by related terms being used interchangeably, such as well-being, health status, and satisfaction. The burdens associated with diabetes, such as anxiety, regimented lifestyle and long-term complications, have prompted researchers and clinicians to examine the impact of the disease on the health-related quality of life (HRQOL) of people with diabetes [7]. Several studies have demonstrated that diabetes has a negative influence on the overall HRQOL and its domains of physical, psychological and social relationships and environment [8] [9] [10].

The DAWN Study (Diabetes Attitudes, Wishes, and Needs) was the world's largest international psychosocial study in persons with diabetes. It included 5000 people with diabetes and 3000 diabetes healthcare professionals across 13 countries. The results of the DAWN Study showed that as many as $41 \%$ of the patients had poor psychological well-being [9].

The aim of this study was to assess the prevalence of depression, anxiety in diabetic patients in our locality and to assess the quality of life in type $2 \mathrm{DM}$.

\section{Subjects \& Methods}

\subsection{Study Locality and Duration}

This study was carried out in outpatient clinics of specialized medical hospital, Mansoura University for a period of one year between 1st March 2013 till 28th February 2014.

\subsection{Study Design}

The study is a cross-sectional comparative study for one-year duration.

\subsection{Target Population}

All patients came to outpatient clinics of specialized medical hospital, Mansoura, Egypt for treatment from type 2 diabetes mellitus (217 subjects). Eight refuse to participate in this study and seven subjects were excluded due to fulfillment of one or more exclusion criteria. Therefore, the study was conducted on 202 patients matched with 247 healthy 
people as a control group. Control subjects were chosen from workers of specialized medical hospital, Mansoura University, Mansoura city. They were medically healthy (No evidence for any disease was found clinically by medicine specialist or by routine general investigations e.g. laboratory test for complete blood picture, liver and kidney function test). Moreover, all control subjects were free from any psychiatric disorders or substance abuse.

An inclusion criterion includes sex, Age range 25 - 70 years old and type 2 diabetes mellitus. Exclusion criteria includes: Type 1 diabetes mellitus; Gestational diabetes; Secondary diabetes due to another disease; The use of medications that affect food intake (Appetite suppressants and other anti-obesity drugs); The incapacity to self completes the questionnaires of depression; and Past history of depression or depression treatment or any other psychiatric illness.

The study was approved by the Mansoura Faculty of medicine, ethics committee, and then it has been performed in accordance with the ethical standards laid down in the 1964 Declaration of Helsinki. A written informed consent was obtained from all participants before inclusion in the study.

\subsection{Study Tools}

All Subjects were examined using especially designed sheet to collect socioeconomic data; clinical data (Comprehensive general examination); and anthropometric examinations to assess body mass index which was calculated as weight divided by height squared $\left(\mathrm{kg} / \mathrm{m}^{2}\right)$ and waist circumference was measured with a flexible tape placed on a horizontal plane at the level of the iliac crest as seen from the anterior view. All patients were interviewed using the Mini-International Neuropsychiatric Interview (MINI) version 5. MINI is a short structured diagnostic interview. The scale had been previously translated and validated into Arabic [11]. All patients were diagnosed using DSM-5 criteria [12]. Furthermore, the severity of anxiety and depression were measured using hospital anxiety and depression scale (HAD) [13]. The Arabic version of the HAD scale was validated by [14]. To examine the impact of the disease on the health-related quality of life (HRQOL) we used the World Health Organization (WHO) quality of life questionnaire, short version (WHOQOL-BREF) [15]. The Arabic version of WHOHRQOL was translated and validated by [7]. The WHOQOL-BREF is a 26-item selfreport instrument, scored on a 5-point scale ranging from one (strongly agree) to five (strongly disagree), with the highest scores representing better HRQOL. There are four sub-scales within the instrument which measure the four domains of HRQOL: physical (e.g. body pain), psychological (e.g. self-esteem), social relationships (e.g. social support), and environment (e.g. physical safety). Laboratory investigation in the form of fasting and two-hour postprandial blood sugar (FBS\& 2hpp) and HbA1C levels were done.

\section{Statistical Methods}

Data were analyzed using SPSS (Statistical Package for Social Sciences) version 20. Qu- 
alitative variables were presented as number and percent. Chi-square was used for comparison between groups. Quantitative variables were tested for normality distribution by Kolomogorov-Smirnov test. Normally distributed variables were presented as mean $\pm \mathrm{SD}$ and unpaired $\mathrm{t}$ test was used for group comparison. Non-parametric variables were presented as median (minimum-maximum). Student t-test was used to compare between two groups. Significant predictors for depression, anxiety, quality of life were entered into a logistic regression analysis using forward Wald methods. Odds ratios (ORs) and their $95 \%$ confidence intervals (CIs) were calculated. $\mathrm{P}$ value less than 0.05 was considered statistically significant.

\section{Results}

37 patients (18.3\%) were found to fulfill DSM-IV-TR criteria for Major depressive disorder; and 5 patients (2.5\%) fulfill Panic attach criteria, other phobia were found in two patients (1\%), generalized anxiety disorder and Obsessive compulsive disorder were found in one patients(0.5\%), No patients was found to be diagnosed as Bipolar disorder, schizophrenia, or substance abuse. In control group, no subject fulfills any DSM-IVTR criteria for any disorder.

Table 1 demonstrated that the only statistically significant difference between control and subjects group were more anxiety and depression with poor quality of life in patients with diabetes than control groups. Anxiety were found to had significant difference between both group diabetic subjects were 86 (42.6\%), 84 (41.6\%) vs. control 3 (1.2\%) 0 (0\%). Depression in diabetic group showed significant difference 35 (17.3\%), 74 (36.6\%) compared to control subjects 5 (2\%) $2(0.8 \%)$. Quality of life in patients with diabetic group showed statistically significant difference 98 (48.5\%) with bad QOL than control groups $0(0 \%)$. Although there were no statistically significant difference between subjects and control groups regarding height, there was statistically significant difference between BMI, with more scores among DM group 29.2260 Vs control 3.86901. Table 2 showed that HbA1c, fasting blood sugar, two hours post prandial blood sugar were more among DM patients and control groups. Anxiety 10.4307, Depression 9.3762, and poorer quality of life were 61.1386 found to be more prevalent among DM patients than control groups Anxiety 4.11860, Depression 4.84250, quality of life 29.50151. Among different predictors for anxiety, depression, quality of life, HBAlc was found to be the only predictor for the three examined variables. In Addition Age was found to be predictor for bad quality of life in DM patients (Table 3). Longer duration of DM and bad control of $\mathrm{HbAlc}$ were found to be associated with more anxiety disorders, more depression, and poorer quality of life (Table 4).

\section{Discussion}

Relation of anxiety disorders and diabetes has not been explored as systematically and extensively as that of depression and diabetes. Anxiety in the context of diabetes has been studied mostly in association with depression [16].

Present study shows that five patients (2.5\%) fulfill panic attack criteria, other pho- 
Table 1. Demonstration of socio-demographic and clinical data of both studied group.

\begin{tabular}{|c|c|c|c|c|c|c|}
\hline & & \multicolumn{2}{|c|}{ Diagnosis } & \multirow{2}{*}{ Total } & \multirow{2}{*}{$\mathrm{X} 2$} & \multirow{2}{*}{$\mathrm{P}$} \\
\hline & & Control & $\mathrm{DM}$ & & & \\
\hline \multirow{2}{*}{ Sex } & Male & $103(41.7 \%)$ & $85(42.1 \%)$ & $188(41.9 \%)$ & \multirow{2}{*}{0.007} & \multirow{2}{*}{0.935} \\
\hline & Female & $144(58.3 \%)$ & $117(57.9 \%)$ & $261(58.1 \%)$ & & \\
\hline \multirow{2}{*}{ Residence } & Urban & $91(36.8 \%)$ & $74(36.6 \%)$ & $165(36.7 \%)$ & \multirow{2}{*}{0.002} & \multirow{2}{*}{0.964} \\
\hline & Rural & $156(63.2 \%)$ & $128(63.4 \%)$ & $284(63.3 \%)$ & & \\
\hline \multirow{2}{*}{ Work } & No work & $113(45.7 \%)$ & $165(81.7 \%)$ & $278(61.9 \%)$ & \multirow{2}{*}{60.85} & \multirow{2}{*}{0.000} \\
\hline & Working & $134(54.3 \%)$ & $37(18.3 \%)$ & $171(38.1 \%)$ & & \\
\hline \multirow{3}{*}{ Anxiety } & Normal & $224(98.8 \%)$ & $32(15.8 \%)$ & $276(61.5 \%)$ & \multirow{3}{*}{322.98} & \multirow{3}{*}{0.000} \\
\hline & Borderline abnormal & $3(1.2 \%)$ & $86(42.6 \%)$ & $89(19.8 \%)$ & & \\
\hline & Abnormal & $0(0 \%)$ & $84(41.6 \%)$ & $84(18.7 \%)$ & & \\
\hline \multirow{3}{*}{ Depression } & Normal & $240(97.2 \%)$ & $93(46 \%)$ & $333(74.2 \%)$ & \multirow{3}{*}{152.63} & \multirow{3}{*}{0.000} \\
\hline & Borderline abnormal & $5(2 \%)$ & $35(17.3 \%)$ & $40(8.9 \%)$ & & \\
\hline & Abnormal & $2(0.8 \%)$ & $74(36.6 \%)$ & $76(16.9 \%)$ & & \\
\hline \multirow{3}{*}{$\begin{array}{l}\text { Degree of } \\
\text { HRQOL }\end{array}$} & Poor or bad HRQOL & $0(0 \%)$ & 98 (48.5\%) & 98 (21.8\%) & \multirow{3}{*}{247.55} & \multirow{3}{*}{0.000} \\
\hline & Moderate HRQOL & $4(1.6 \%)$ & $47(23.3 \%)$ & $51(11.4 \%)$ & & \\
\hline & High HRQOL & $243(98.4 \%)$ & $57(28.2 \%)$ & $300(66.8 \%)$ & & \\
\hline \multirow{2}{*}{\multicolumn{2}{|c|}{ Total }} & 247 & 202 & 449 & & \\
\hline & & $100.0 \%$ & $100.0 \%$ & $100.0 \%$ & & \\
\hline
\end{tabular}

Table 2. Demonstration of data and scores for anthropometric examinations, psychiatric scales, and laboratory test.

\begin{tabular}{|c|c|c|c|c|c|c|}
\hline & \multicolumn{2}{|c|}{$\mathrm{DM}(202)$} & \multicolumn{2}{|c|}{ Control (247) } & & \multirow{2}{*}{$P$} \\
\hline & Mean & Std. Deviation & Mean & Std. Deviation & & \\
\hline Body mass index & 29.2260 & 3.86901 & 32.6400 & 3.14405 & -10.316 & 0.000 \\
\hline Weight & 74.7673 & 8.77527 & 83.6316 & 6.27858 & 12.45 & 0.000 \\
\hline Height & 160.1733 & 4.82476 & 160.2834 & 4.71986 & -0.244 & 0.808 \\
\hline $\mathrm{HbAlC}$ & 7.2649 & 0.98390 & 9.3279 & 0.40594 & -29.98 & 0.000 \\
\hline Fasting blood sugar & 241.3515 & 30.16984 & 89.9879 & 11.95230 & 72.24 & 0.000 \\
\hline $\begin{array}{l}2 \text { hours Post-Prandial } \\
\text { blood sugar }\end{array}$ & 309.0000 & 32.86063 & 165.6235 & 15.29892 & 60.98 & 0.000 \\
\hline Anxiety Score & 10.4307 & 4.11860 & 4.6073 & 1.58615 & 20.45 & 0.000 \\
\hline Depression Score & 9.3762 & 4.84250 & 4.4899 & 1.98749 & 14.44 & 0.000 \\
\hline Quality of life (Physical) & 61.1386 & 29.50151 & 88.0567 & 12.51295 & -12.99 & 0.000 \\
\hline $\begin{array}{l}\text { Quality of life } \\
\text { (psychological) }\end{array}$ & 44.3069 & 25.40253 & 85.2227 & 13.30730 & -21.9 & 0.000 \\
\hline Quality of life (social) & 49.0099 & 27.29988 & 70.3441 & 23.39531 & -8.92 & 0.000 \\
\hline $\begin{array}{l}\text { Quality of life } \\
\text { (environmental) }\end{array}$ & 44.3069 & 27.06202 & 84.0081 & 13.98053 & -20.02 & 0.000 \\
\hline Total & 49.6906 & 21.87169 & 81.9079 & 7.67809 & -21.59 & 0.000 \\
\hline
\end{tabular}


Table 3. Demonstration of logistic regression analysis for depression, anxiety, and quality of life.

\begin{tabular}{ccccccccccc}
\hline Dependent Variable & \multicolumn{3}{c}{ Depression } & \multicolumn{3}{c}{ Anxiety } & \multicolumn{4}{c}{ Quality of life } \\
\hline Model & $\begin{array}{c}\mathrm{SQ}^{*} \\
\text { Beta }\end{array}$ & $\mathrm{T}$ & $\mathrm{P}$. & $\begin{array}{c}\mathrm{SQ}^{*} \\
\text { Beta }\end{array}$ & $\mathrm{T}$ & $\mathrm{P}$ & $\begin{array}{c}\mathrm{SQ}^{*} \\
\text { Beta }\end{array}$ & $\mathrm{T}$ & $\mathrm{P}$ \\
& & 0.421 & 0.675 & & 2.333 & 0.021 & & -1.339 & 0.182 \\
(Constant) & & & & & & & & & & \\
Age & 0.090 & 1.425 & 0.156 & 0.002 & 0.055 & 0.956 & -0.109 & -2.949 & 0.004 \\
Weight & 0.546 & 0.601 & 0.549 & 0.408 & 0.975 & 0.331 & -0.445 & -0.831 & 0.407 \\
Height & -0.271 & -0.584 & 0.560 & -0.188 & -0.878 & 0.381 & 0.240 & 0.878 & 0.381 \\
Body mass index & -0.638 & -0.619 & 0.537 & -0.461 & -0.973 & 0.332 & 0.552 & 0.910 & 0.364 \\
HbA1C & -0.189 & -3.016 & 0.003 & -0.924 & -32.093 & 0.000 & 0.837 & 22.739 & 0.000 \\
Fasting blood sugar & -0.028 & -0.453 & 0.651 & -0.028 & -1.011 & 0.313 & -0.034 & -0.934 & 0.351 \\
2 hours Post & 0.479 & 7.908 & 0.000 & -0.027 & -0.986 & 0.326 & 0.066 & 1.850 & 0.066 \\
Prandial blood sugar & & & & & & & & \\
\hline
\end{tabular}

$\mathrm{SSQ}^{*}$ : Standardizes; ${ }^{*}$ : standardized coefficients.

Table 4. Study effect of DM duration and HbAlc on the presence or absence on anxiety and depression and quality of life.

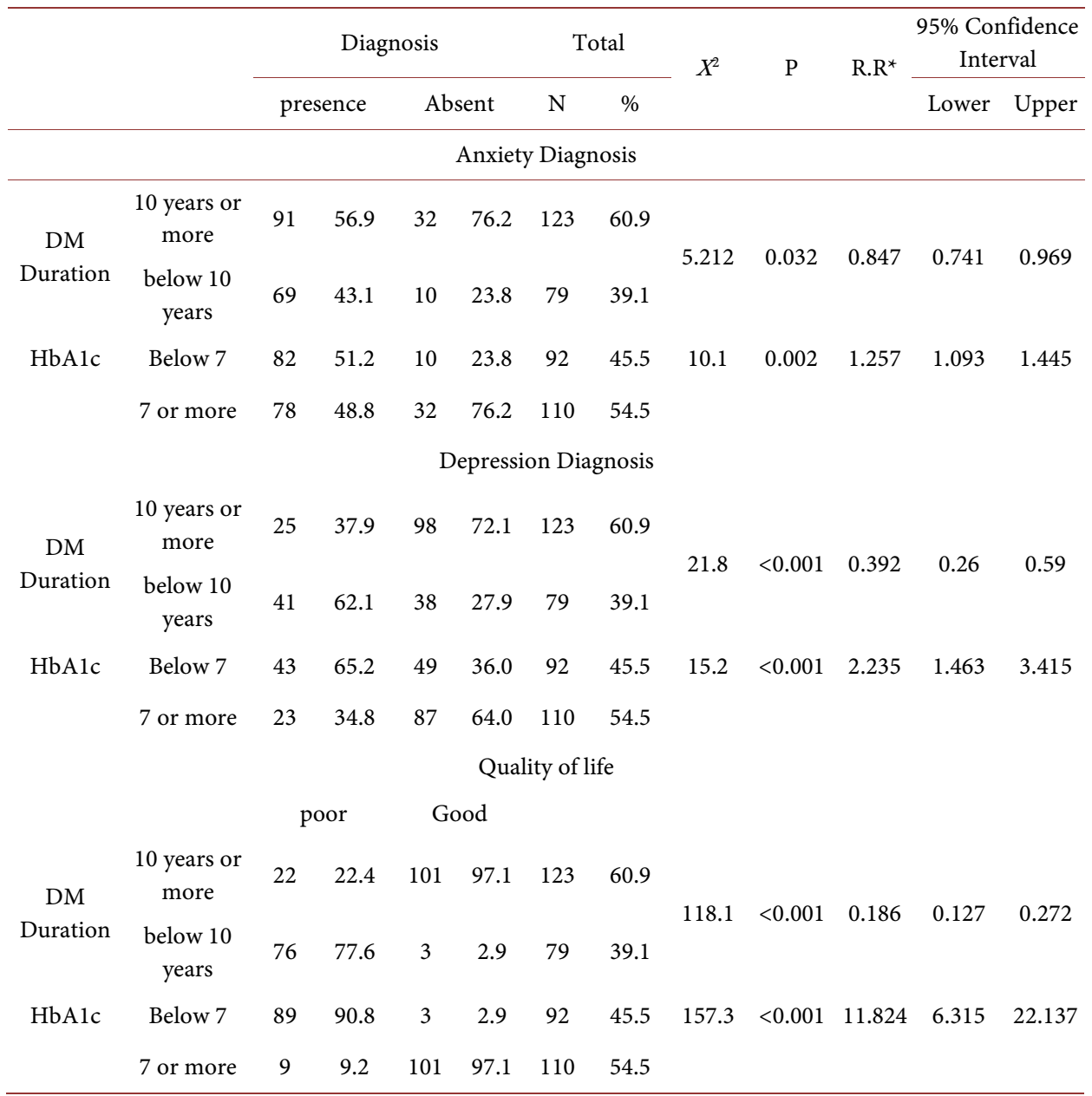


bia are found in two patients (1\%), generalized anxiety disorder and obsessive compulsive disorder are found in one patient $(0.5 \%)$, no patients are found to be diagnosed as bipolar disorder, schizophrenia, or substance abuse. In control group, no subject fulfills any DSM-IV-TR criteria for any disorder. Anxiety symptoms have been found to be significant risk factors for development of diabetes [5]. Negative correlations have been observed between prevalence of anxiety disorders and levels of HbA1c [6].

Clinical features such as sweating, anxiety, tremor, tachycardia, and confusion are shared by both hypoglycemic episodes and anxiety disorders. This could present a diagnostic challenge especially among individuals having phobia of hypoglycemic episodes. Chronically anxious individuals may be more likely either to fail to perceive the initial warning signs of hypoglycemia or to confuse these with anxiety [16]. Moreover, medications used in management of anxiety disorders such as SSRIs, benzodiazepines, and beta adrenergic blockers could potentially interfere with glycemic control and normal physiological warning signs of an impending hypoglycemic episode [16].

Present study shows that, thirty-seven patients (18.3\%) were found to fulfill DSMIV-TR criteria for major depressive disorder depression and diabetes shared a bidirectional causal association. Depression has been postulated to play a causal role in emergence of diabetes. A meta-analysis has reported that depressed individuals have a $60 \%$ increased risk of developing diabetes [17]. A specific association has been found between risk of developing diabetes and non-severe depression, persistent depression, and untreated depression [18]. Similarly, diabetes has been recognized as a "depressogenic" condition [19]. Biochemical changes (including neuro-endocrinal changes such as hyper-cortisolemia, leptin activity in limbic system, altered glucose transportation, proinflammatory cytokines) associated with diabetes or its treatment, psychological factors (such as stress associated with living with diabetes, poor treatment adherence), and behavioral factors (sedentary lifestyles, smoking, overeating) have been implicated in this causal association [20]. There is a modest association between use of most antidepressants and incidence of diabetes with long-term use of antidepressants at moderate or higher doses increasing risk of diabetes by almost two fold [2]. Similarly factors such as poor diet, habitual inactivity, excessive nicotine use, psychotropic medications used for treatment of bipolar disorder have been implicated in association between BPAD and diabetes.

Present study found that poor quality of life was found to be more prevalent among diabetic patients with longer duration and with bad control of blood sugar. A number of studies have been done to assess health-related quality of life in patients with diabetes [21] [22]. In general, these studies have been able to demonstrate a reduced quality of life in patients with diabetes [9]. The quality of life of diabetic patients is significantly reduced in the presence of both microvascular and macrovascular complications [3] [9] [23]. Poor quality of life in these patients is attributable to psychological effects of reduced general well-being, lack of acceptance and support from family members, feelings of restriction when complying with treatment, and self-monitoring strategies among others [3] [9] [23]. Vileikyte reported a poor quality of life in patients 
with foot involvement [22]. An assessment of patients with diabetic neuropathy using the Nottingham Health Profile showed that symptomatic diabetic neuropathy was associated with impaired quality of life in five out of six domains: emotional reaction, energy, pain, physical mobility, and sleep [24].

From our study, we can conclude that anxiety and depression were associated with hyperglycemia and poor metabolic control, which may increase the risk of complications from T2DM. Recognition of all psychiatric co-morbidities among individuals with diabetes is suboptimal, therefore global approaches to establish coordinated, multifaceted interventions to improve early recognition and early initiation of treatment for all psychiatric commodities are required to reduce the burden among individuals with diabetes; this may achieve greater efficiency and success in the treatment of T2DM.

Therefore, our recommendation is that it would be advantageous to have other longitudinal studies to better understand the nature of those associations between diabetes and different psychiatric illness. Diabetes health professionals require basic training in identification and management of associated psychiatric illness in patients with diabetes. In our locality, there is a need for adequate communication/interview skills, motivational techniques and counseling skills for health professionals treating individuals with diabetes. Effective management of patients with diabetes and psychiatric co morbidities requires collaborative efforts between a number of health care disciplines, including primary care, endocrinology, psychiatry, psychology, nursing, pharmacy, and allied health professions.

\section{Limitations of the Study}

First limitation in our study is the small number of patients. The second limitation is that we have done our study in one center that was Internal Medicine Hospital (diabetes clinic and diabetes inpatient department), Mansoura University instead of being multicenter. These limitations are due to high cost needed to include large numbers of patients in different centers.

\section{Compliance with Ethical Standards}

1) There is no fund to our study.

2) Author 1) Alaa Wafa has no conflict of interest. Author 2) Mohamed Adel El-Hadidy has no conflict of interest.

3) The study was approved by the Mansoura Faculty of Medicine, ethics committee, and then it has been performed in accordance with the ethical standards laid down in the 1964 Declaration of Helsinki and its later amendments or comparable ethical standards.

4) A written informed consent was obtained from all participants before inclusion in the study.

\section{References}

[1] Young, E.E. and Unachukwu, C.N. (2012) Psychosocial Aspects of Diabetes Mellitus. Afri- 
can Journal of Diabetes Medicine, 20, 5-7.

[2] Anderson, F., Schade, R., Suissa, S. and Garbe, E. (2009) Long-Term Use of Antidepressants for Depressive Disorders and the Risk of Diabetes Mellitus. The American Journal of Psychiatry, 166, 591-598. https://doi.org/10.1176/appi.ajp.2008.08071065

[3] Rubin, R.R. and Peyrot, M. (1992) Psychosocial Problems and Interventions in Diabetes: A Review of the Literature. Diabetes Care, 15, 1640-1657. https://doi.org/10.2337/diacare.15.11.1640

[4] Huang, C.J., Chiu, H.C., Lee, M.H. and Wang, S.Y. (2011) Prevalence and Incidence of Anxiety Disorders in Diabetic Patients: A National Population-Based Cohort Study. General Hospital Psychiatry, 33, 8-15. https://doi.org/10.1016/j.genhosppsych.2010.10.008

[5] Engum, A. (2007) The Role of Depression and Anxiety in Onset of Diabetes in a Large Population-Based Study. Journal of Psychosomatic Research, 62, 31-38.

https://doi.org/10.1016/j.jpsychores.2006.07.009

[6] Hermanns, N., Kulzer, B., Krichbaum, M., Kubiak, T. and Haak, T. (2005) Affective and Anxiety Disorders in a German Sample of Diabetic Patients: Prevalence, Co Morbidity and Risk Factors. Diabetic Medicine, 22, 293-300. https://doi.org/10.1111/j.1464-5491.2005.01414.x

[7] Bani-Issa, W. (2011) Evaluation of the Health-Related Quality of Life of Emirati People with Diabetes: Integration of Sociodemographic and Disease-Related Variables. Eastern Mediterranean Health Journal, 17, 825-830.

[8] Ribu, L., Hanestad, B.R., Moum, T., Birkeland, K. and Rustoen, T. (2007) Health-Related Quality of Life among Patients with Diabetes and Foot Ulcers: Association with Demographic and Clinical Characteristics. Journal of Diabetes and Its Complications, 21, 227 236. https://doi.org/10.1016/j.jdiacomp.2007.02.001

[9] Peyrot, M., Rubin, R.R., Lauritzen, T., Snoek, F.J., Matthews, D.R. and Skovlund, S.E. (2005) Psychosocial Problems and Barriers to Improved Diabetes Management: Results of the Cross-National Diabetes Attitudes, Wishes and Needs (DAWN) Study. Diabetic Medicine, 22, 1379-1385. https://doi.org/10.1111/j.1464-5491.2005.01644.x

[10] Abdel Gadir, M., Shebeika, W., Eltom, M., Berne, C. and Wikblad, K. (2009) Health Related Quality of Life and Sense of Coherence in Sudanese Diabetes Subjects with Lower Limb Amputations. Tohoku Journal of Experimental Medicine, 217, 45-50.

[11] Sadek, A. (2000) Mini International Neuropsychiatric Interview (MINI): The Arabic Translation. In: Psychiatry Update, Vol. 2, Institute of Psychiatry, 23-31.

[12] American Psychiatric Association (2013) Diagnostic and Statistic Manual of Mental Disorders. 5th Edition, American Psychiatric Association Press, Washington DC.

[13] Zigmond, A.S. and Snaith, R.P. (1983) The Hospital Anxiety and Depression Scale. Acta Psychiatrica Scandinavica, 67, 361-370. https://doi.org/10.1111/j.1600-0447.1983.tb09716.x

[14] el-Rufaie, O.E. and Absood, G.H. (1995) Retesting the Validity of the Arabic Version of the Hospital Anxiety and Depression (HAD) Scale in Primary Health Care. Social Psychiatry and Psychiatric Epidemiology, 30, 26-31.

[15] The WHOQOL Group (1998) Development of the World Health Organization WHOQOLBREF Quality of Life Assessment. Psychological Medicine, 28, 551-558. https://doi.org/10.1017/S0033291798006667

[16] Balhara, Y.P.S. (2011) Diabetes and Psychiatric Disorders. Indian Journal of Endocrinology and Metabolism, 15, 274-283. https://doi.org/10.4103/2230-8210.85579

[17] Mezuk, B., Eaton, W.W., Albrecht, S. and Golden, S.H. (2008) Depression and Type 2 Diabetes over the Lifespan: A Meta-Analysis. Diabetes Care, 31, 2383-2390. 
https://doi.org/10.2337/dc08-0985

[18] Campayo, A., de Jonge, P., Roy, J.F., Saz, P., de la Cámara, C., Quintanilla, M.A., et al. (2010) Depressive Disorder and Incident Diabetes Mellitus: The Effect of Characteristics of Depression. The American Journal of Psychiatry, 167, 580-588. https://doi.org/10.1176/appi.ajp.2009.09010038

[19] Pan, A., Lucas, M., Sun, Q., van Dam, R.M., Franco, O.H., Manson, J.E., et al. (2010) Bidirectional Association between Depression and Type 2 Diabetes Mellitus in Women. Archives of Internal Medicine, 170, 1884-1891. https://doi.org/10.1001/archinternmed.2010.356

[20] Talbot, F. and Nouwen, A. (2000) A Review of the Relationship between Depression and Diabetes in Adults: Is There a Link? Diabetes Care, 23, 1556-1562. https://doi.org/10.2337/diacare.23.10.1556

[21] Koopmanschap, N., on behalf of the CODE-2 Advisory Board (2002) Coping with Type 2 Diabetes: The Patient's Perspective. Diabetologia, 45, S18-S22. https://doi.org/10.1007/s00125-002-0861-2

[22] Vileikyte, L. (2008) Diabetic Foot Ulcers: A Quality of Life Issue. Diabetes/Metabolism Research and Reviews, 17, 246-249. https://doi.org/10.1002/dmrr.216

[23] (2002) The Oxford International Diabetes Summit: Implications of the DAWN Study. Practical Diabetes International, 19, 187-192.

[24] Benbow, S.J., Wallymahmed, M.E. and MacFarlane, I.A. (1998) Diabetic Peripheral Neuropathy and Quality of Life. The Quarterly Journal of Medicine, 91, 733-737. https://doi.org/10.1093/qjmed/91.11.733

\section{Submit or recommend next manuscript to SCIRP and we will provide best service for you:}

Accepting pre-submission inquiries through Email, Facebook, LinkedIn, Twitter, etc. A wide selection of journals (inclusive of 9 subjects, more than 200 journals)

Providing 24-hour high-quality service

User-friendly online submission system

Fair and swift peer-review system

Efficient typesetting and proofreading procedure

Display of the result of downloads and visits, as well as the number of cited articles Maximum dissemination of your research work

Submit your manuscript at: http://papersubmission.scirp.org/

Or contact ijcm@scirp.org 